\title{
Social perception of wearing masks: An exploratory study
}

\author{
Tayeba Khatun ${ }^{1 *}$
}

\section{ABSTRACT}

Covid-19 changed our daily lifestyle in different ways, may it be in the form of social distancing, lockdowns, or wearing masks. Masks will be included in long run as a daily essential accessory even when the situation becomes normal. Thus, impression formation, perception, schema and related phenomenon of stereotyping are sure to be effected. This study is an attempt to explore the probable facial features and type of masks that provides the perceiver a cue to make a rough idea of occupation to which the person wearing the mask is associated with. The qualitative analysis of the data provides us a clear understanding that there lies a pattern or basic idea of which mask type is most likely to be used by which professional. Also, there is an underlying pattern in which particular facial features are associated with a job type. This study clearly directs for future studies on similar grounds.

\section{Keywords: Masks, COVID-19, Social Perception}

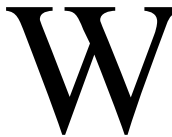

ith the sudden onset of SARS-CoV-2 i.e. Severe acute respiratory syndrome Corona virus 2, the world faced several dramatic changes including social distancing, complete lockdowns and even using face masks as a ritual (Feng.et.al, 2020). The social life of all is severely affected in a way or other and the way people used to perceive others. Using any face masks is found to decrease exposure and infection risk on a population level (van der Sande M. et.al, 2008) and thus people across the globe are motivated to make and wear self-made masks as they are cost efficient and don't develop the crisis for medical masks as they are highly needed by the ones associated with the medical field (Carbon, 2020). This new compulsion will soon turn into fashion trend and will be followed religiously. Carbon (2020) stated that face mask will be seen in different social situations in long run. However, it is a new addition to the facial features that people will use in perceiving others and creating impressions about others. Literature reviewed by Shen.et.al (2019) exhibited that people can quickly infer traits of personality from face alone and in their own study participants were found to form implicit impression through trustworthiness of faces. It is quite clear through the literature that faces provide people cues to form impression and it affect their behavior towards the person in some way or the other. Facial features do add important information about emotional state, gender, personality and even behavior (Carré and McCormick, 2008). And the most important finding is that these cues are considered in every then and now situation from choosing a partner, friend, employee or even suspecting a criminal.

\footnotetext{
${ }^{1}$ Student MA Psychology, Cotton University, Guwahati, Assam, India *Responding Author
}

Received: August 20, 2020; Revision Received: October 4, 2020; Accepted: October 20, 2020

(C) 2020, Khatun T.; licensee IJIP. This is an Open Access Research distributed under the terms of the Creative Commons Attribution License (www.creativecommons.org/licenses/by/2.0), which permits unrestricted use, distribution, and reproduction in any Medium, provided the original work is properly cited. 


\section{Social perception of wearing masks: An exploratory study}

While adding and supporting the above ideas it was found that black complexion or stereotypically black faces is often associated with criminal category (Kleider.et.al, 2012). Similar results were supported for Black women that stated that Black women or women with darker complexion were treated differently than women having lighter complexion in terms of prison sentences, who were more leniently sentenced and served less in prison than Black women (Viglione, Hannon, and DeFina. 2011). However interestingly, a study on facial cues and trustworthiness found that dark complexion faces were rated as more trustworthy by both Chinese and Caucasian participants and added that participants used facial attractiveness cues for judging trustworthiness (Xu.F. et.al, 2012). Zebrowitz \& Montepare (1992) studied childlike faces and revealed that faces having round face, thin eyebrows, a small nose bridge and large eyes distinguished as childlike faces and individuals having babyface were thought to have more childlike attributes than mature faced individuals.

Bereczkei and Mesko studied the length of hair length and attractiveness of women as perceived by men. They revealed that women having neotenous facial features like large eyes, small nose were perceived as most attractive. A large pool of literature too adds that these cues of perception were somehow or the other was related to or are similar to the attractiveness cues.

The current study thus focuses to ascertain the way in which wearing masks adds to facial characteristics information and derived conclusions.

\section{METHODOLOGY}

\section{Participants}

Participants between the ages of 15 to 71 years volunteered to participate where 64 Male, 44 female and 1 of the participants identified himself as other. They did not know the person whose faces were used in the experiment. Participants gave informed consent before the experiment and they were assured for safeguarding their information.

\section{Variables}

The portraits used were the composite face generated by the researchers using morphing method including images of 20 most attractive male and female faces respectively (Duggal.et.al,2016).These two portraits from their study was then manipulated using facial feature manipulation applications to generate 32 male portraits with 4 mask types and 32 female portraits with 4 mask types for Job categories of Doctors, Soldiers, Artists, Murderer and Thief.

\section{Procedure}

A closed ended questionnaire including the pictures generated by manipulation applications was forwarded online to the participants. Participants were asked to associate the faces with the some neutral (Artist) or negative (Thief and murderer) or positive (Doctor, and Soldier) jobs for every category of mask type (i.e. having eight options varying on facial features).

\section{RESULTS}

The data collected is represented in Tables and categorized under different job profile titles and subdivided into different mask types and gender. 


\section{Doctor}

The data in Table-1 indicates that out of total respondents, $18.35 \%$ of the respondents believed that men having narrow forehead are more likely to match their perception of Doctors wearing white masks.

Only $4.58 \%$ of respondents believed that men having thin eyebrows are Doctors. While the responses for female portraits wearing plain white masks, indicates that $27.52 \%$ of the respondents believed that females having oval face are more likely to be Doctors. Whereas only $3.67 \%$ of the respondents chose large eyes as a facial feature to be associated with female Doctors wearing white masks.

The data also indicates that $15.59 \%$ respondents supported that None of the faces of male wearing FFP2 mask resembles to a Doctor. While $13.76 \%$ of the respondents went with the idea that men having oval face are more likely to be a doctor. The least number of respondents believed that Men having large eyes are likely to be a doctor. Among the 109 respondents $11.0 \%$ believed Dark complexion is associated with Female doctors wearing FFP2 mask, while none of the respondents chose large eyes. Only $4.58 \%$ of the respondents believed that thin eyebrows are associated with female doctors.

$24.78 \%$ of the respondents chose none of the male portraits wearing black mask to be a doctor. While $12.84 \%$ of the respondents chose male portrait having Dark complexion to be a doctor and only, 5.50\% respondents chose large eyes to be associated with Male doctors wearing black masks. Majority (19.99\%) of the respondents believed that oval face is more closely associated with female doctors out of the portraits wearing Black mask. While only $2.75 \%$ of the respondents chose large eyes as a feature to be associated with female doctors wearing black masks.

$26.60 \%$ of the respondents chose none of the options while $11.0 \%$ believed that Narrow forehead is more closely associated with male doctors out of the portraits wearing Printed masks. Whereas only $3.66 \%$ of the respondents chose large eyes as a feature to be associated with male doctors wearing printed masks. Also, $20.18 \%$ believed that oval face is more closely associated with female doctors out of the portraits wearing Printed masks. Whereas only $0.91 \%$ of the respondents chose Large eyes as a feature to be associated with female doctors wearing printed masks.

Table-1 represents the frequency for each facial feature perceived to be associated with Doctors

\begin{tabular}{|c|c|c|c|c|c|c|c|c|c|c|c|}
\hline $\begin{array}{c}\text { Mask } \\
\text { Type }\end{array}$ & Gender & $\begin{array}{c}\text { Narrow } \\
\text { forehead }\end{array}$ & $\begin{array}{c}\text { Broad } \\
\text { Forehead }\end{array}$ & $\begin{array}{c}\text { Large } \\
\text { Eyes }\end{array}$ & $\begin{array}{c}\text { Small } \\
\text { eyes }\end{array}$ & $\begin{array}{c}\text { Round } \\
\text { face }\end{array}$ & $\begin{array}{c}\text { Oval } \\
\text { face }\end{array}$ & $\begin{array}{c}\text { Thick } \\
\text { eyebrows }\end{array}$ & $\begin{array}{c}\text { Thin } \\
\text { eyebrows }\end{array}$ & $\begin{array}{c}\text { Dark } \\
\text { Complexion }\end{array}$ & None \\
\hline \multirow{2}{*}{ White } & Male & 20 & 14 & 6 & 8 & 10 & 9 & 10 & 5 & 9 & 18 \\
\cline { 2 - 13 } & Female & 8 & 13 & 4 & 6 & 7 & 30 & 5 & 12 & 14 & 10 \\
\hline \multirow{2}{*}{ FFP2 } & Male & 10 & 13 & 5 & 6 & 14 & 15 & 8 & 10 & 11 & 17 \\
\cline { 2 - 13 } & Female & 9 & 12 & 0 & 12 & 13 & 21 & 11 & 5 & 14 & 12 \\
\hline \multirow{2}{*}{ Black } & Male & 11 & 11 & 6 & 8 & 7 & 10 & 8 & 7 & 14 & 27 \\
\cline { 2 - 12 } & Female & 8 & 11 & 3 & 10 & 6 & 20 & 13 & 8 & 15 & 15 \\
\hline \multirow{2}{*}{ Printed } & Male & 12 & 10 & 4 & 8 & 15 & 5 & 10 & 5 & 11 & 29 \\
\cline { 2 - 11 } & Female & 6 & 11 & 1 & 8 & 11 & 22 & 13 & 11 & 8 & 18 \\
\hline
\end{tabular}


Social perception of wearing masks: An exploratory study

Table-2 represents the frequency for each facial feature perceived to be associated with Soldiers

\begin{tabular}{|c|c|c|c|c|c|c|c|c|c|c|c|}
\hline $\begin{array}{c}\text { Mask } \\
\text { Type }\end{array}$ & Gender & $\begin{array}{c}\text { Narrow } \\
\text { forehead }\end{array}$ & $\begin{array}{c}\text { Broad } \\
\text { Forehead }\end{array}$ & $\begin{array}{c}\text { Large } \\
\text { Eyes }\end{array}$ & $\begin{array}{c}\text { Small } \\
\text { eyes }\end{array}$ & $\begin{array}{c}\text { Round } \\
\text { face }\end{array}$ & $\begin{array}{c}\text { Oval } \\
\text { face }\end{array}$ & $\begin{array}{c}\text { Thick } \\
\text { eyebrows }\end{array}$ & $\begin{array}{c}\text { Thin } \\
\text { eyebrows }\end{array}$ & $\begin{array}{c}\text { Dark } \\
\text { Complexion }\end{array}$ & None \\
\hline \multirow{2}{*}{ White } & Male & 7 & 5 & 5 & 6 & 9 & 15 & 12 & 8 & 23 & 19 \\
\cline { 2 - 12 } & Female & 16 & 4 & 6 & 9 & 17 & 8 & 19 & 4 & 10 & 16 \\
\hline \multirow{2}{*}{ FFP2 } & Male & 10 & 7 & 8 & 8 & 7 & 6 & 15 & 5 & 23 & 20 \\
\cline { 2 - 12 } & Female & 5 & 6 & 8 & 8 & 10 & 16 & 18 & 3 & 18 & 17 \\
\hline \multirow{2}{*}{ Black } & Male & 9 & 7 & 4 & 8 & 14 & 6 & 12 & 7 & 28 & 14 \\
\cline { 2 - 11 } & Female & 14 & 6 & 5 & 11 & 14 & 5 & 17 & 5 & 17 & 15 \\
\hline \multirow{2}{*}{ Printed } & Male & 15 & 5 & 6 & 4 & 10 & 13 & 12 & 7 & 18 & 19 \\
\cline { 2 - 11 } & Female & 9 & 6 & 8 & 3 & 14 & 19 & 12 & 7 & 13 & 18 \\
\hline
\end{tabular}

Table-3 represents the frequency for each facial feature perceived to be associated with Artists

\begin{tabular}{|l|c|c|c|c|c|c|c|c|c|c|c|}
\hline $\begin{array}{l}\text { Mask } \\
\text { Type }\end{array}$ & Gender & $\begin{array}{c}\text { Narrow } \\
\text { forehead }\end{array}$ & $\begin{array}{c}\text { Broad } \\
\text { Forehead }\end{array}$ & $\begin{array}{c}\text { Large } \\
\text { Eyes }\end{array}$ & $\begin{array}{c}\text { Small } \\
\text { eyes }\end{array}$ & $\begin{array}{c}\text { Round } \\
\text { face }\end{array}$ & $\begin{array}{c}\text { Oval } \\
\text { face }\end{array}$ & $\begin{array}{c}\text { Thick } \\
\text { eyebrows }\end{array}$ & $\begin{array}{c}\text { Thin } \\
\text { eyebrows }\end{array}$ & $\begin{array}{c}\text { Dark } \\
\text { complexion }\end{array}$ & None \\
\hline \multirow{2}{*}{ White } & Male & 13 & 7 & 7 & 9 & 7 & 19 & 9 & 14 & 7 & 17 \\
\cline { 2 - 12 } & Female & 11 & 12 & 8 & 11 & 6 & 20 & 5 & 13 & 7 & 16 \\
\hline \multirow{2}{*}{ FFP2 } & Male & 5 & 12 & 11 & 11 & 15 & 10 & 9 & 10 & 9 & 17 \\
\cline { 2 - 12 } & Female & 9 & 9 & 14 & 12 & 10 & 18 & 6 & 3 & 9 & 19 \\
\hline \multirow{2}{*}{ Black } & Male & 11 & 6 & 11 & 18 & 5 & 11 & 10 & 13 & 6 & 18 \\
\cline { 2 - 11 } & Female & 12 & 5 & 13 & 7 & 7 & 19 & 10 & 10 & 8 & 18 \\
\hline \multirow{2}{*}{ Printed } & Male & 17 & 4 & 9 & 12 & 9 & 9 & 12 & 16 & 5 & 16 \\
\cline { 2 - 11 } & Female & 14 & 9 & 11 & 12 & 11 & 15 & 9 & 5 & 9 & 14 \\
\hline
\end{tabular}

Table-4 represents the frequency for each facial feature perceived to be associated with Murderers

\begin{tabular}{|c|c|c|c|c|c|c|c|c|c|c|c|}
\hline $\begin{array}{c}\text { Mask } \\
\text { Type }\end{array}$ & Gender & $\begin{array}{c}\text { Narrow } \\
\text { forehead }\end{array}$ & $\begin{array}{c}\text { Broad } \\
\text { Forehead }\end{array}$ & $\begin{array}{c}\text { Large } \\
\text { Eyes }\end{array}$ & $\begin{array}{c}\text { Small } \\
\text { eyes }\end{array}$ & $\begin{array}{c}\text { Round } \\
\text { face }\end{array}$ & $\begin{array}{c}\text { Oval } \\
\text { face }\end{array}$ & $\begin{array}{c}\text { Thick } \\
\text { eyebrows }\end{array}$ & $\begin{array}{c}\text { Thin } \\
\text { eyebrows }\end{array}$ & $\begin{array}{c}\text { Dark } \\
\text { Complexion }\end{array}$ & None \\
\hline \multirow{2}{*}{ White } & Male & 6 & 10 & 11 & 7 & 5 & 9 & 18 & 5 & 16 & 22 \\
\cline { 2 - 12 } & Female & 7 & 5 & 17 & 10 & 10 & 8 & 17 & 6 & 10 & 19 \\
\hline \multirow{2}{*}{ FFP2 } & Male & 8 & 8 & 12 & 11 & 10 & 5 & 16 & 5 & 12 & 22 \\
\cline { 2 - 12 } & Female & 7 & 8 & 16 & 16 & 12 & 12 & 6 & 4 & 8 & 20 \\
\hline \multirow{2}{*}{ Black } & Male & 9 & 14 & 10 & 15 & 6 & 5 & 10 & 3 & 19 & 18 \\
\cline { 2 - 11 } & Female & 11 & 2 & 15 & 12 & 14 & 9 & 8 & 8 & 12 & 18 \\
\hline \multirow{2}{*}{ Printed } & Male & 4 & 7 & 11 & 9 & 7 & 10 & 13 & 9 & 17 & 22 \\
\cline { 2 - 11 } & Female & 6 & 12 & 15 & 11 & 11 & 8 & 8 & 8 & 11 & 19 \\
\hline
\end{tabular}

Table-5 represents the frequency for each facial feature perceived to be associated with Thieves

\begin{tabular}{|l|c|c|c|c|c|c|c|c|c|c|c|}
\hline $\begin{array}{l}\text { Mask } \\
\text { Type }\end{array}$ & Gender & $\begin{array}{c}\text { Narrow } \\
\text { forehead }\end{array}$ & $\begin{array}{c}\text { Broad } \\
\text { Forehead }\end{array}$ & $\begin{array}{c}\text { Large } \\
\text { Eyes }\end{array}$ & $\begin{array}{c}\text { Small } \\
\text { eyes }\end{array}$ & $\begin{array}{c}\text { Round } \\
\text { face }\end{array}$ & $\begin{array}{c}\text { Oval } \\
\text { face }\end{array}$ & $\begin{array}{c}\text { Thick } \\
\text { eyebrows }\end{array}$ & $\begin{array}{c}\text { Thin } \\
\text { eyebrows }\end{array}$ & $\begin{array}{c}\text { Dark } \\
\text { Complexion }\end{array}$ & None \\
\hline \multirow{2}{*}{ White } & Male & 7 & 7 & 6 & 17 & 5 & 9 & 13 & 11 & 13 & 21 \\
\cline { 2 - 12 } & Female & 8 & 3 & 7 & 16 & 16 & 12 & 8 & 9 & 8 & 22 \\
\hline \multirow{2}{*}{ FFP2 } & Male & 10 & 12 & 9 & 14 & 7 & 6 & 8 & 10 & 12 & 21 \\
\cline { 2 - 12 } & Female & 7 & 2 & 10 & 15 & 13 & 9 & 9 & 4 & 14 & 26 \\
\hline \multirow{2}{*}{ Black } & Male & 7 & 9 & 9 & 19 & 9 & 4 & 15 & 10 & 11 & 16 \\
\cline { 2 - 11 } & Female & 9 & 5 & 10 & 9 & 15 & 6 & 12 & 10 & 14 & 19 \\
\hline \multirow{2}{*}{ Printed } & Male & 6 & 5 & 11 & 12 & 8 & 12 & 16 & 8 & 11 & 20 \\
\cline { 2 - 11 } & Female & 10 & 11 & 9 & 14 & 7 & 14 & 3 & 8 & 11 & 22 \\
\hline
\end{tabular}


Social perception of wearing masks: An exploratory study

Table-6 represents the frequency for each mask type perceived to be associated with Job type

\begin{tabular}{|l|l|l|l|l|l|l|}
\hline & Gender & $\begin{array}{l}\text { White } \\
\text { Masks }\end{array}$ & FFP2 Masks & $\begin{array}{l}\text { Black } \\
\text { Masks }\end{array}$ & $\begin{array}{l}\text { Printed } \\
\text { Masks }\end{array}$ & None \\
\hline \multirow{2}{*}{ Doctor } & Male & 35 & 30 & 21 & 7 & 16 \\
\cline { 2 - 7 } & Female & 33 & 38 & 13 & 11 & 14 \\
\hline \multirow{3}{*}{ Artist } & Male & 15 & 17 & 45 & 12 & 20 \\
\cline { 2 - 7 } & Female & 13 & 18 & 39 & 22 & 17 \\
\hline \multirow{3}{*}{ Murderer } & Male & 18 & 12 & 19 & 43 & 17 \\
\cline { 2 - 7 } & Female & 21 & 12 & 17 & 40 & 19 \\
\cline { 2 - 7 } Thief & Female & 14 & 10 & 37 & 18 & 30 \\
& Male & 19 & 8 & 42 & 11 & 35 \\
\cline { 2 - 7 } & Female & 9 & 10 & 40 & 7 & 33 \\
\hline
\end{tabular}

\section{Soldier}

Table-2 represents that $21.10 \%$ of the respondents chose male portraits having dark complexion wearing white mask to be a soldier. While only, $4.58 \%$ respondents chose broad forehead and another group of $4.58 \%$ respondents chose Large eyes to be associated with soldiers. Data represents that $17.43 \%$ of the respondents chose female portraits having Thick eyebrows wearing white mask to be a soldier. While only, 3.66\% respondents chose broad forehead to be associated with female soldiers. This finding is similar to that of male soldiers where least respondents chose Broad forehead to be a trait associated with Soldiers.

Data gathered represents that $25.68 \%$ of the respondents went with male portraits having dark complexion wearing black mask to be a soldier. While only, 3.67\% respondents chose large eyes to be associated with male soldiers. This is similar to the earlier findings of male portraits having white masks. $15.59 \%$ of the respondents went with female portraits having dark complexion wearing black mask to be a soldier and another $15.59 \%$ participants went with Thick eyebrows to be associated with female soldiers. The findings are parallel with the earlier findings. While only, $4.58 \%$ respondents chose large eyes, another group of $4.58 \%$ chose thin eyebrows and rest $4.58 \%$ believed oval face to be associated with female soldiers wearing black masks. This is similar to the earlier findings of male portraits having white masks.

Data gathered for FFP2 masks represents that $21.10 \%$ of the respondents went with male portraits having dark complexion to be a soldier. The findings are parallel with the earlier findings. While only, $4.58 \%$ respondents chose thin eyebrows to be associated with male soldiers. $16.51 \%$ of the respondents went with female portraits having dark complexion wearing black mask to be a soldier. The findings are parallel with the earlier findings. While only, $2.75 \%$ respondents chose thin eyebrows to be associated with female soldiers, which is similar to the data gathered for male portraits and same mask type.

For printed masks, $17.43 \%$ of the respondents chose none of the portraits, as similar to their prototype of soldier while $16.51 \%$ went with male portraits having dark complexion to be a soldier. The findings are parallel with the earlier findings. While only, 3.66\% respondents chose small eyes to be associated with male soldiers. Bargraph-18 represents that $17.43 \%$ of the respondents female portraits having oval face wearing printed mask to be a soldier. While only, $2.75 \%$ respondents chose small eyes to be associated with female soldiers. Which is similar with findings in case of portraits of male soldiers wearing printed masks. 


\section{Artists}

Table 3, represents that $17.43 \%$ of the respondents chose male portraits having oval face wearing white mask to be an Artist. While only, $6.42 \%$ respondents chose dark complexion to be associated with male Artists, while another group of $6.42 \%$ chose round face in addition to $6.42 \%$ of respondents who chose large eyes to be a trait of Artist. Bargraph-22 indicates that $18.34 \%$ of the respondents went with female portraits having oval face wearing white mask to be an Artist. This similar to what is found for male artists. While only, $4.58 \%$ respondents chose thick eyebrows to be a trait of Artist.

Data in the table indicates that $16.51 \%$ of the respondents chose male portraits having small eyes wearing black mask to be an Artist. While only, $4.58 \%$ respondents chose round face to be a trait of Artist.17.43\% of the respondents chose female portraits having oval face and wearing black mask to be an Artist. While only, $4.58 \%$ respondents chose female face with broad head to be a trait of Artist.

For FFP2 masks, $15.59 \%$ of the respondents chose none of the male portraits, while $13.76 \%$ chose portrait chose round face to be an Artist. While only, $4.58 \%$ respondents chose male face with narrow forehead to be a trait of Artist. $17.43 \%$ of the respondents chose none of the female portraits, while $16.51 \%$ chose portrait chose oval face and wearing FFP2 mask to be an Artist. While only, $2.75 \%$ respondents chose female face with thin eyebrows to be a trait of Artist.

For portraits with printed masks, $15.59 \%$ of the respondents chose narrow forehead and wearing printed mask to be an Artist. While only, 3.67\% respondents chose male face with broad forehead to be a trait of Artist. $13.76 \%$ of the respondents chose oval face, while only, $4.58 \%$ respondents chose female face with large eyes to be a trait of Artist.

\section{Murderer}

The data in Table 4 indicates that out of total respondents, $20.18 \%$ chose none of the portraits and $16.51 \%$ of the respondents believed that men having thick eyebrows are likely to be a murderer, and only $4.58 \%$ of respondents chose round face to be associated with male murderers and another group of $4.58 \%$ of respondents chose oval face to be associated with male murderers wearing white masks. The data collected for female portraits indicates that out of total respondents, $17.43 \%$ chose none of the portraits and $15.59 \%$ of the respondents believed that women having thick eyebrows are likely to be a murderer, and another group of $15.59 \%$ chose large eyes to be trait of female murderer. Only $4.58 \%$ of respondents chose broad forehead to be associated with female murderers among nine female portraits wearing white masks.

The data for black masks indicates that out of total respondents, $17.43 \%$ chose dark complexion to be a trait likely to be found in male murderers. Only $2.75 \%$ of respondents chose thin eyebrows to be associated with male murderers among nine male portraits wearing black masks. The data indicates that out of total respondents, $16.51 \%$ chose none as their choice, while $13.76 \%$ went with Large eyes to be a trait likely to be found in female murderers. Only $1.83 \%$ of respondents chose broad forehead to be associated with female murderers among nine portraits wearing black masks.

The data also indicates that out of total respondents, $20.18 \%$ chose none as their choice, while $14.67 \%$ went with thick eyebrows to be a trait likely to be found in male murderers wearing FFP2 masks. Only $4.58 \%$ of respondents chose oval face and another $4.58 \%$ of the 


\section{Social perception of wearing masks: An exploratory study}

respondents went with the idea of thin eyebrows to be associated with male murderers among nine portraits wearing FFP2 masks. The data in Bargraph-36 indicates that out of total respondents, $18.34 \%$ chose none as their choice, while $14.67 \%$ went with large eyes to be a trait likely to be found in female murderers, which quite similar to the data collected for other type of masks in category of murderers. Only $3.67 \%$ of respondents went with the idea of thin eyebrows to be associated with female murderers among nine portraits wearing FFP2 masks.

The data for portraits wearing printed masks indicates that out of total respondents, $20.18 \%$ chose none as their choice, while $15.59 \%$ went with dark complexion to be a trait likely to be found in male murderers. Only $3.67 \%$ of respondents went with the idea of narrow forehead to be associated with male murderers among nine portraits wearing printed masks. The data also indicates that out of total respondents, $17.43 \%$ chose none as their choice, while $13.76 \%$ went with large eyes to be a trait likely to be found in female murderers. Only $5.50 \%$ of respondents went with the idea of narrow forehead to be associated with female murderers among nine portraits wearing printed masks, which is similar to the earlier findings for male counterparts.

\section{Thieves}

The data in Table 5 indicates that out of total respondents, $19.26 \%$ chose none as their choice, while $15.59 \%$ went with small eyes to be a trait likely to be found in male thief wearing white masks. Only $4.58 \%$ of respondents chose round face to be associated with male thieves among nine portraits wearing white masks. The data indicates that out of total respondents, $20.18 \%$ chose none as their choice, while $14.67 \%$ went with small eyes to be a trait likely to be found in female thief similar to their male counterparts while another group of $14.67 \%$ went with round face to be associated with the female thieves. Only $2.75 \%$ of respondents chose broad forehead to be associated with female thieves among nine portraits wearing white masks.

The data also indicates that out of total respondents, $17.43 \%$ went with small eyes to be a trait likely to be found in male thief similar to the male portraits wearing black masks. Only $3.67 \%$ of respondents chose oval face to be associated with male thieves among nine portraits wearing black masks. The data in table 5 indicates that out of total respondents, $17.43 \%$ chose none of the portraits, $13.76 \%$ went with round face to be a trait likely to be found in female thieves. Only $4.58 \%$ of respondents chose broad forehead to be associated with female thieves among nine portraits wearing black masks.

For portraits with FFP2 masks, $19.26 \%$ chose none of the portraits, $12.84 \%$ went with small eyes to be a trait likely to be found in male thieves. Only $5.50 \%$ of respondents chose oval face to be associated with male thieves. The data indicates that out of total respondents, $23.85 \%$ chose none of the portraits, $13.76 \%$ went with small eyes to be a trait likely to be found in female thieves. Only $1.83 \%$ of respondents chose broad forehead to be associated with female thieves among nine portraits wearing FFP2 masks.

The data for printed masks indicates that out of total respondents, $18.34 \%$ chose none of the portraits, $14.67 \%$ went with thick eyebrows to be a trait likely to be found in male thieves. Only $4.58 \%$ of respondents chose broad forehead to be associated with male thieves among nine portraits wearing printed masks. The data in Bargraph-48 indicates that out of total respondents, $20.18 \%$ chose none of the portraits, $12.84 \%$ went with small eyes to be a trait 
likely to be found in female thieves. Only $2.75 \%$ of respondents chose thick eyebrows to be associated with female thieves among nine portraits wearing printed masks.

\section{Masks types and perceived jobs}

The data in Table -6 indicates that out of total respondents, $32.11 \%$ of the respondents believed that men wearing plain white masks to match their perception of Doctors and only $6.42 \%$ of respondents believed that men wearing printed masks are Doctors. While data for females indicate that out of total respondents, $34.86 \%$ of the respondents believed that women wearing FFP2 masks, match their perception of Doctors and only $10.09 \%$ of respondents believed that women wearing printed masks are Doctors. Also, the results show that least number of respondents i.e. only $10.09 \%$ of the participants felt that printed masks might be used by female doctors.

Out of total respondents, $41.28 \%$ of the respondents believed that men wearing black masks to match their perception of Soldiers and only $11.0 \%$ of respondents chose Printed masks to be used by soldiers And out of total respondents, $35.77 \%$ of the respondents believed that women wearing black masks, match their perception of Soldiers and only $11.92 \%$ of respondents chose white masks to be used by soldiers. The idea of using black masks by female soldiers is similar to the findings for male portraits.

The data indicates that out of total respondents, $39.44 \%$ of the respondents believed that men wearing printed masks, are much more likely to be an artist and only $11.0 \%$ of respondents chose FFP2 to be used by male artists. While for females the data collected indicates that out of total respondents, $36.69 \%$ of the respondents believed that women wearing printed masks, are much more likely to be an artist and only $11.0 \%$ of respondents chose FFP2 to be used by male artists. The results very well match with the data for the portraits of male, where respondents chose printed masks to be most likely to be used by artist. The reason might be that they Artists are thought to be creative and liking designs and patterns rather than plain texture.

The data also indicates that out of total respondents, $33.94 \%$ of the respondents believed that black masks are more likely to be used by male murderers and only $9.17 \%$ of respondents chose FFP2 to be used by male murderers. While for females, out of total respondents, $38.53 \%$ of the respondents believed that black masks are more likely to be used by female murderers as similar to the male counterparts and only $7.33 \%$ of respondents chose FFP2 to be used by female murderers. This finding is also similar to that of the males.

The data represented in Table- 6 indicates that out of total respondents, $36.69 \%$ of the respondents believed that black masks are more likely to be used by male thieves just like murderers and only $6.42 \%$ of respondents chose printed masks to be used by male thieves. Also, out of total respondents, $33.02 \%$ of the respondents believed that black masks are more likely to be used by female thieves just like murderers and their male thieves and only $8.25 \%$ of respondents chose white to be used by female thieves.

\section{DISCUSSION}

The results clearly outline the fact that there is a huge similarity or an underlying pattern between the responses of the participants. Thus, it can also be understood that people do associate a particular facial feature with a particular job along with the idea that a particular type of mask is highly likely to be used by a particular kind of people or people associated with a particular job. 


\section{Social perception of wearing masks: An exploratory study}

In case of doctors' portraits, narrow forehead is the most commonly supported trait thought to be present in a male doctor irrespective of the mask used. While in case of female doctors, oval shape is associated most of the time irrespective of the mask used. However, there is also an underlying pattern noticed in the case of least number of people supported the idea of a doctor having large eyes irrespective of gender and mask used.

In case of the doctors both plain white mask and FFP2 masks are mostly associated with doctors irrespective of gender and least number of the participants believed that printed masks are to be used by Doctors irrespective of Gender of portraits. The reason behind these findings might be that since respondents must have experienced white plain surgical masks to be used in medical environment and must have encountered Doctors generally wearing white masks. Similar is the responses associated with FFP2 mask. Since recently these masks were highly recommended and used by medical professionals, and somehow the idea of doctors wearing FFP masks is accommodated in the prototype of doctors. Since, handmade masks are suggested to be used by general public since unavailability of medical masks was reported and government asked people to use handmade masks so that surgical and Filtering face piece masks can be used by people who are in front line fighting with Covid-19 like medical professionals and Covid-19 patients. And the results run parallel to the data for male portraits.

In case of Soldiers, dark complexion is thought to be a trait associated with soldiers, by most of the participants, irrespective of the mask and gender portraits. The reason behind maximum respondents believed Dark complexion as one of the traits to be associated with Soldier since they are trained hard under the sun and there is huge probability that soldiers will grow dark under normal circumstances. However Broad forehead is the least preferred option in case of White masks for both gender portraits, large eyes is least preferred in case of black masks in both gender, small eyes is least preferred in case of Printed masks, and Thin eyebrows is the least preferred irrespective of gender in case of soldiers wearing FFP2 masks.

Also, in case of Mask type, Soldiers are found to be associated with Black masks irrespective of gender categories and least associated is printed and white masks. The reason behind this finding might be that soldiers are using black as a bandana or any other accessory is preferred to be black if not the camouflage color since ages in any defence service. Also, recently the senior officers of Indian Army discussed on the matter of wearing masks that go with the uniform, although no particulars orders have been passed yet but since masks will be a necessity in future thus there is concern to put proper guidelines (Pandit,2020, TOI). Although Black and white is the most used colours along with camouflage pattern for masks in case of Soldiers. (Pandit, 2020, TOI). While viewing the findings for the least group of responses in case of printed masks, it is least probable to add anything for soldiers that don't go with their uniform and might disrupt the uniform etiquettes.

In case of Artist oval face type is the most preferred in case of females and for the category of white masks for males. However, an overall pattern is hard to specify for facial feature that participants thought to be associated with Artists. But there is visible similarity in case of choice of masks for Artists, as maximum participants believed that Printed Masks best fit with Artists and least number of participants believed that artists will use FFP2 masks. The reason behind this might be Artists are non-conformist creative people and they are thought to look for creative designs and patterns for everything associated with them. 
In case of Murderers, most of the participants believed that dark complexion, thick eyebrows and Large eyes are the traits to be associated with Murderers. Also, narrow forehead is expected as a trait in Murderers in case of both male and female portraits with Printed masks by least number of respondents. Also, most of the respondents believed that murderers are likely to use a black mask and least number of participants chose FFP2 masks. Black is viewed or associated with bad stimuli since ages. In case of thieves, small eyes are the most supported trait to be of a thief irrespective of gender. While least number of respondents chose broad forehead to be a trait of thieves. While similar to the findings for murderers, most of respondents thought that, thieves are also likely to prefer black masks irrespective of gender and least number of respondents chose Printed and white masks as thief's' preference.

Also, there is a huge pattern observed in case of the basic idea of judging a person on the basis of their portraits. In almost every case people showed a reluctance to associate a person in terms of their facial features to any occupation, although there is a similarity in what their idea for a male or female prototype about a particular job is. However, the reluctance in form of "None" responses is mostly observed in case of negatively viewed jobs like murderer and thief irrespective of gender.

\section{CONCLUSION}

There is a clear pattern observed in case of particular job profiles as how people perceive men and women associated with a particular job type to be. It might be the job characteristics, job duties that make employees similar like in case of Defense personnel and thus effects the way a person perceives a person to be associated with a particular job. Also, a huge similarity is found in case of use of mask. As in the case of Artists, people expected printed mask to be most likely used by an artist whether male or female. Thus, considering the present study further studies can be conducted, with implementing proper measures that ensures elimination of the limitations encountered in the present study. Using a larger sample, focusing on particular facial feature or a particular mask type to get insight of this topic on which we can build our further concepts.

\section{REFERENCES}

Baudouin, Jean-Yves \& Tiberghien, Guy. (2004). Symmetry, averageness, and feature size in the facial attractiveness of women. Acta psychologica. 117. 313-32. 10.1016/j.actpsy.2004.07.002.

Bereczkei, T., \& Mesko, N. (1970, January 01). Hair length, facial attractiveness, personality attribution: A multiple fitness model of hairdressing. Retrieved July 07, 2020, from https://hrcak.srce.hr/9060

Carbon, Claus-Christian, The Psychology of Wearing Face Masks in Times of the COVID19 Pandemic (April 24, 2020). Retrived from SSRN:

https://ssrn.com/abstract=3584834 or http://dx.doi.org/10.2139/ssrn.3584834

Duggal, S., Kapoor, D., Verma, S., Sagar, M., Lee, Y., Moon, H., \& Rhee, S. (2016, March 18). Photogrammetric Analysis of Attractiveness in Indian Faces. Retrieved July 07, 2020, from https://doi.org/10.5999/aps.2016.43.2.160

Dumas, Rafaële \& Testé, Benoît. (2006). The Influence of Criminal Facial Stereotypes on Juridic Judgments. Swiss Journal of Psychology/Schweizerische Zeitschrift für Psychologie/Revue Suisse de Psychologie. 65. 237-244. 10.1024/14210185.65.4.237.

Feng, Shuo \& Shen, Chen \& Xia, Nan \& Song, Wei \& Fan, Mengzhen \& Cowling, Benjamin. (2020). Rational use of face masks in the COVID-19 pandemic. The Lancet Respiratory Medicine. 8. 10.1016/S2213-2600(20)30134-X. 
Justin M Carré and Cheryl M McCormick (2008) In your face: facial metrics predict aggressive behaviour in the laboratory and in varsity and professional hockey playersProc. R. Soc. B.2752651-2656

Kleider, Heather \& Cavrak, Sarah \& Knuycky, Leslie. (2012). Looking like a criminal: Stereotypical Black facial features promote face source memory error. Memory \& cognition. 40. 10.3758/s13421-012-0229-x.

Miller, E. (1969). Body Image, Physical Beauty and Color Among Jamaican Adolescents. Social and Economic Studies, 18(1), 72-89. Retrieved May 15, 2020, from www.jstor.org/stable/27856365

Mogilski, J., \& Welling, L. (2018, November 19). The Relative Contribution of Jawbone and Cheekbone Prominence, Eyebrow Thickness, Eye Size, and Face Length to Evaluations of Facial Masculinity and Attractiveness: A Conjoint Data-Driven Approach. Retrieved July 07, 2020, from https://www.frontiersin.org/articles/10.3389/fpsyg.2018.02428/full

Mueller U, Mazur A (1997) Facial dominance in Homo sapiens as honest signaling of mate quality. Behavioral Ecology 8: 569-579

Rajat Pandit / TNN / Updated: May 23, 2. (2020). Covid-19: Colour of masks presents military with tough poser: India News - Times of India. Retrieved July 07, 2020, from https://timesofindia.indiatimes.com/india/colour-of-masks-presents-military-with-toughposer/articleshow/75905237.cm

Rule NO, Ambady N (2008) The face of success: inferences from chief executive officers' appearance predict company profits. Psychol Sci 19: 109-111.

Shen, X., Mann, T., \& Ferguson, M. (2019, November 07). Beware a dishonest face? Updating face-based implicit impressions using diagnostic behavioral information. Retrieved July 07, 2020, from https://www.sciencedirect.com/science/article/pii/S0022103118308503

Tipples, J., Atkinson, A. P., \& Young, A. W. (2002). The eyebrow frown: A salient social signal. Emotion, 2(3), 288-296. https://doi.org/10.1037/1528-3542.2.3.288

Todorov A, Mandisodza AN, Goren A, Hall CC (2005) Inferences of competence from faces predict election outcomes. Science 308: 1623-1626,37-38

Xu F, Wu D, Toriyama R, Ma F, Itakura S, et al. (2012) Similarities and Differences in Chinese and Caucasian Adults' Use of Facial Cues for Trustworthiness Judgments. PLoS ONE 7(4): e34859. doi: 10.1371/journal.pone.0034859

Zebrowitz, Leslie \& Montepare, Joann. (1992). Impressions of babyfaced individuals across the life-span. Developmental Psychology. 28. 1143-1152. 10.1037/0012-1649.28.6.1143.

\section{Acknowledgement}

The author appreciates all those who participated in the study and helped to facilitate the research and would like to acknowledge her indebtedness and render my warmest thanks to Dr. Suresh Kumar Scientist 'E', Strategic Behavior Division, DIPR, DRDO, Delhi and Miss Shraboni Bhagwati, Guest Faculty, Department of Psychology, Cotton University who made this work possible. Their guidance and expert advice have been invaluable throughout all stages of the work. Author would also express her gratitude to both her guides for extended discussions and valuable suggestions which have contributed greatly to the improvement of this work.

\section{Conflict of Interest}

The author declared no conflict of interest.

How to cite this article: Khatun T. (2020). Social perception of wearing masks: An exploratory study. International Journal of Indian Psychology, 8(4), 49-59. DIP:18.01.008/20200804, DOI:10.25215/0804.008 